\title{
Reconstrucción del Pabellón Auricular con Cartílago Costal Autólogo en Microtias - Técnica del Prof. Juarez Moraes Avelar, Primer Tiempo Quirúrgico.
}

\section{EAR AURICLE RECONSTRUCTION WITH AUTOLOGOUS COSTAL CARTILAGE IN MICROTIAS- PROFESSORJUAREZ MORAES AVELAR TECHNIQUE, FIRST SURGICAL STAGE.}

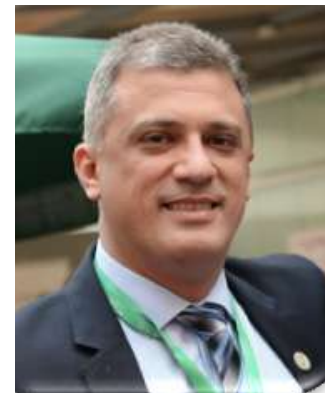

Suárez Oyhamburú Darío Lautaro*

Cirujano Plástico, Titular SBCPER, FILACP, ICOPLAST.

Clínica Niño Jesús Dos. Santa Cruz de la Sierra, Bolivia.

\section{Resumen.}

La reconstrucción del pabellón auricular es aún una cirugía poco frecuente en nuestro medio. La OMS reporta que 1 de cada 8000 nacidos vivos, presenta algún grado de malformación congénita auricular. En el presente trabajo utilizo la clasificación de Microtias de Avelar con sus características particulares que así las determina en severas o moderadas y empleo el modelo del tallado del cartílago autólogo también descrito por mi profesor.

Dos son los tiempos operatorios principales aunque dejo un tercero para realizar afinamientos estéticos que sean necesarios. La edad apropiada para operar oscila entre los 6 a 8 años de edad donde la oreja sana ha alcanzado el $80 \%$ del tamaño total y las costillas alcanzan un volumen considerable para ser talladas.

Retiro el cartílago de la 8va. y/o 9na. costilla siempre del lado derecho y no así del lado izquierdo, tanto para las microtias del mismo lado como para las microtias del lado izquierdo, en este caso simplemente se evierte el segmento cartilaginoso a tallar guiándome con un molde de un pedacito de una radiografía tomado de la oreja sana contra lateral. No tengo experiencia empleando prótesis auriculares de silicona, porex, medpor o poliuretano.

Dos son los pasos que sigo a la hora de operar cuando determino el tipo de Microtia presentada: 1ero. Modelar el es- queleto cartilaginoso y 2do. Lograr una cobertura cutánea del área temporo mastoidea que es muy poco distensible.

\section{Abstract.}

The ear auricle reconstruction is one of the least frequent surgeries in our country. The WHO reports that for every 8000 new borns, one presents a congenital auricular pavilion anomaly.

In the following study I use Avelar's microtia classification according to the particular characteristics that each one possess. I also work with an autologous carved cartilage that is as well described by my professor.

There are two principal stages used for this type of surgery, however I leave a third one to work on any aesthetical improvement if needed. The recommended ages for this kind of surgery are between six and eight years old, once the normal ear has reached about $80 \%$ of its size and the ribs have a volume big enough to be used for carving.

I remove the cartilage from the 8th and/ or 9th rib. It is on the right rib I always work on even though the microtia could be on the left side. I easily invert the cartilage segment to be carved using a piece of R-X film as a model from the opposite health ear. I don't have any experience using silicone, porex, medpor, nor polyurethane auricle prothesis.

There are two steps I follow when I determine the type of 
Microtia. The first one is to model the cartilage. The second one is to try to have a cutaneous coverage from the temporal mastoidea area difficult to spread.

\section{Palabras Claves.}

Reconstrucción del Pabellón Auricular, Cartílago Autólogo, Microtia Severa y Moderada.

\section{Key Words.}

Ear Auricle Reconstruction, Autologous Cartilage, Severe and Moderate Microtia.

\section{Introducción.}

La palabra Microtia y Anotia son palabras derivadas del griego que significan respectivamente oreja pequeña o ausencia de la oreja en el caso de las anotias. Me rijo exclusivamente a utilizar la clasificación sobre las malformaciones del pabellón auricular empleadas por el Profesor Juárez Avelar, publicadas inicialmente en 1986, con quien tuve la inmensa satisfacción de acogerme en sus enseñanzas durante mi periodo de formación en la ciudad de Sao Paulo en el año 2003, y además participar como colaborador en la organización en el III Curso de Reconstrucción de Oreja, organizado por el Instituto De la Oreja del Prof. Avelar, en el Hospital del Corazón de Sao Paulo, Brasil.

Es muy importante emplear los términos correctos dentro del vocabulario médico y diferenciar la terminología apropiada para cada caso de malformación del pabellón auricular. De tal manera que ANOTIA, se emplea para definir una malformación congénita donde NO existe ningún vestigio de cartílago auricular ni del conducto auditivo externo (CAE). Este término de Anotia fue citado por primera vez en el año 1858 por Nysten-Littre para referirse a la ausencia de la oreja (1). AGENESIA AURICULAR, a los casos de ausencia del cartílago auricular pero con presencia del cartílago tragal y del CAE. Así como MICROTIA a las deformidades con disminución del tamaño del pabellón auricular. Y aquí se abre una inmensa gama de clasificaciones y especificaciones de acuerdo con los segmentos cartilaginosos presentes y característicos en cada malformación. Por ejemplo Rogers clasifica a las microtias moderadas a aquellas, con alteraciones en la Helix, Concha y Escafa auricular denominándolos "Lop" "y "Cup" Ear según la alteración presente y característica en cada una. Ya Tanzer en 1971 las describió como "Constricted Ear" a las microtias con ciertas características clásicas (oreja retorcida) para su denominación. $(1,3,4)$.

No podemos de ninguna manera dejar de mencionar a las constantes publicaciones en Francia de la Prof. Francoise Firmin (9)y el Prof. Satoru Nagata con innumerables publicaciones y con una inmensa experiencia en reconstrucción de oreja en Japón(10), así como también al Dr. Burt Brent de Estados Unidos quien publica una cuantía impresionan- te de más de 1900 casos de reconstrucción de oreja en 3 a 4 tiempos quirúrgicos. $(6,7,8)$ También existen interesantes trabajos descritos en Colombia por el Dr. Gabriel Osorno actualmente con más de 540 Casos descritos y con resultados tan interesantes que fueron publicados en el "Journal of Plastic and Reconstructive Surgery en 1999 pero en aquella época relato la experiencia de 110 casos. Mi Profesor el Dr. Juárez Avelar ha reportado a lo largo de su vida profesional una experiencia de más de 2000 casos operados. (5)

Todos con aportes importantes y para quienes gozan y aman de este pequeño segmento de la cirugía reconstructiva se hace apasionante pero imposible de describir a cada uno de estos "Gigantes" en la reconstrucción de oreja.

Por este motivo y por las enseñanzas en mí depositadas es que mencionare únicamente los aspectos técnicos y me basare en la clasificación del Prof. Avelar.

Las Microtias pueden ser Moderadas o Severas y esta clasificación responde a las características estructurales del tejido cartilaginoso, a la presencia de lóbulo de la oreja, si está presente o no el conducto auditivo externo (CAE), si existe parte de la concha o está ausente, y si también se encuentra el trago o nó.(1,2,3,4)

La presencia de estas deformaciones son más comunes en el sexo masculino que en el femenino y predominan mayormente en el lado derecho más que en el izquierdo y en mi práctica privada también coincide con la experiencia del Dr. Avelar. Sin embargo presento una prevalencia de 2 a 1 en relación del lado derecho al izquierdo... es decir por dos Microtias a la derecha existe una en la izquierda. Esto claro en mi modesta experiencia. Pero en algunos casos se pueden presentar diferentes malformaciones en ambos lados en el mismo paciente como el caso abajo mostrado para caracterizar cada tipo de Microtia con sus respectivas características.

La edad indicada para operar esta malformación oscila entre los 6 a 8 años, donde el cartílago costal ha alcanzado un tamaño necesario como para poder utilizarlo en la reconstrucción, así mismo el pabellón auricular sano alcanza el 80 \% de su tamaño definitivo y se hace más fácil definir el tamaño apropiado del cartílago que será usado. También juega un papel importante que no podemos dejar de lado que es el aspecto psicológico, pues en mi pequeña experiencia los niños de esta edad presentan ya complejos y disturbios psicológicos producto de la presión ejercida por los otros niños en el colegio y el deseo de operarse está presente e inclusive el post operatorio es muy llevadero con mejores resultados. $(2,3,4)$.

A continuación observamos en la misma paciente de 8 años de edad con ambos tipos de microtias: en primer lugar 
Microtia Severa con sus características y en segundo lugar, Microtia Moderada con sus características peculiares que la clasifican como tal. (Figura 1 y 2)

Microtia Severa.(figura 1)

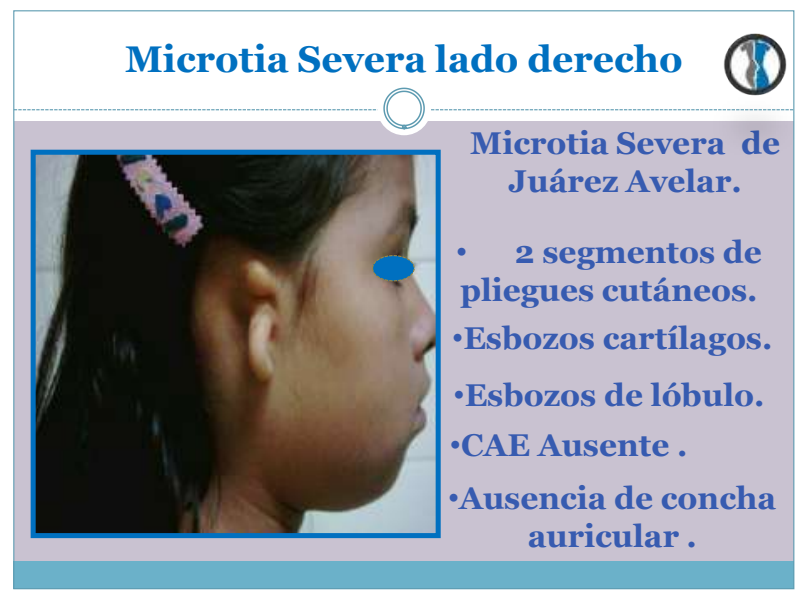

Microtia Moderada. (Figura 2)

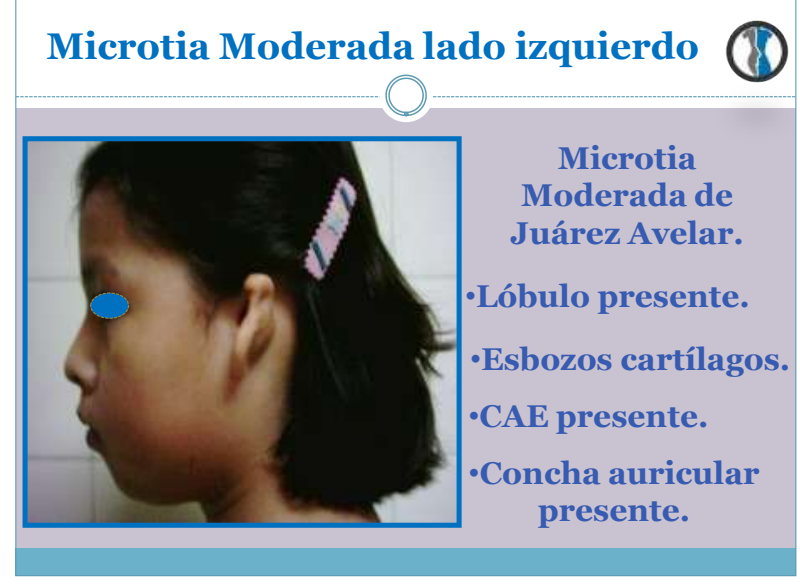

Para cada tipo de malformación hay una técnica quirúrgica diferente y considero que las Microtias moderadas implican un grado mayor de dificultad técnica operatoria debido a la cantidad de cartílago embrionario mal formado $(2,3)$, aunque principalmente la técnica se base en dos tiempos quirúrgicos básicos a veces es necesario un tercero, simplemente para la corrección de cicatrices inestéticas u otros pequeños detalles para afinar los resultados trazados. El primer tiempo quirúrgico comienza con la retirada del cartílago costal de la 8va. o de la 9na. costilla, siempre del lado derecho ya que cuando la malformación es del lado izquierdo simplemente se evierte el segmento cartilaginoso y se realiza el tallado del neo cartílago auricular de la misma manera que como si fuera una malformación del lado derecho. El segundo tiempo lo realizamos después del 6 to mes post operación y utilizo para cubrir el segmento disecado del área temporal y mastoidea un colgajo cervical y/o injertos parciales de cuero cabelludo del área temporal para evitar cicatrices en otras zonas del cuerpo. $(4,5)$
No tengo por conducta el uso de Prótesis Siliconadas, Poliuretano, o de Prótesis de Medpor o Porex únicas o recubiertas con aponeurosis temporal para la reconstrucción aunque en la literatura de aun encontremos esta modalidad técnica descrita.

En lo particular creo que a la larga esos materiales extraños al cuerpo debido a la delicadeza de la piel de la región temporo-mastoidea que es utilizada para la reconstrucción no soportarían y terminarían extruyéndose.

La técnica empleada para el tallado del cartílago de preferencia ocupa una sola pieza.....aunque a veces es necesario otro segmento cartilaginosos para la confección del trago. Lo importante es reconstruir la curvatura del hélix hasta su raíz y lógicamente también las otras estructuras dándole una naturalidad lo cercana posible al pabellón reconstruido. $(2,3)$. No uso hilos metálicos por más fino que sean, la tendencia a causar extrusión está siempre presente o fistulas que pongan en riesgo la reconstrucción. Si fuera necesario utilizar hilos de sutura tengo preferencia por el Prolene 4 -o aguja vascular con menos posibilidad de lastimar el segmento cartilaginoso trabajado, aunque en ausencia de Prolene también uso el Nylon 4-0.

No aconsejo la reconstrucción del orificio del CAE por tres motivos importantes (1):

1. Riesgo de lesionar el nervio facial.

2. Posibilidad de osteomielitis de mastoides secundaria a cirugía otológica.

3. Cirugías previas dejan cicatrices que dificultan la expansión al generar fibrosis en el área y no otorgan buen resultado al momento de calcarse la piel al cartílago tallado.

El modelo del tallado empelado es el de Avelar como se puede observar en el cuadro inferior (4). (Figura 3).

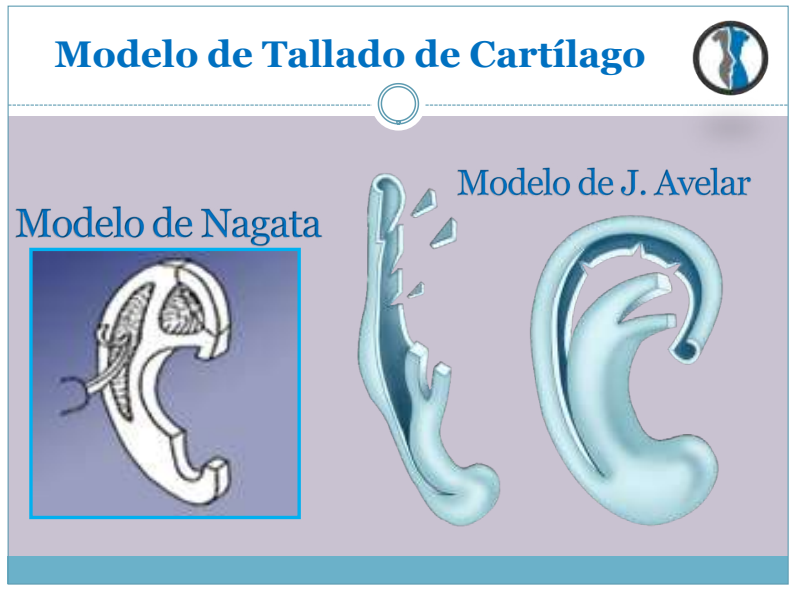

\section{Material y Métodos.}

Dos son los objetivos que me trazo cuando planifico una reconstrucción de oreja y son: Primero, el tallado del esqueleto cartilaginoso y Segundo la cobertura cutánea que 
dependerá del tipo de Microtia presentada, del área glabra de la región temporo mastoidea, de la presencia o no de cicatrices previas.

Al momento de ejecutar la obtención del segmento cartilaginoso intentamos preservar la mayor cantidad de pericondrio para que exista una regeneración del tejido extraído y así evitar deformaciones futuras de la parrilla costal.

También a medida que vamos finalizando el reparado del pericondrio, realizamos la "prueba del neumático" $(1,2)$ que consiste en colocar suero fisiológico en la cavidad y pedimos al anestesiólogo que insufle al paciente para que durante la expansión pulmonar observemos que no existe lesión de la pleura parietal, es decir si durante la expansión se forman burbujas en el suero fisiológico vertido probablemente hubo lesión pleural y la posibilidad de neumotórax debe servalorada.

Felizmente en mis manos nunca he presentado esta desagradable complicación. (Figura 4).

(Figura 4).

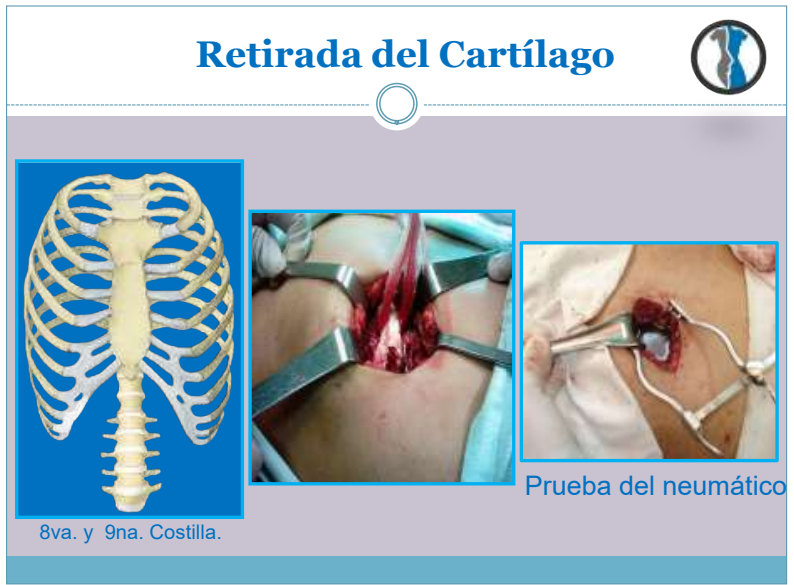

Empleo una sonda Foley durante el trans operatorio para lograr expandir la piel temporo mastoidea de la siguiente manera: por lo general insuflamos el Balón con 5 a $10 \mathrm{mls}$ de suero fisiológico por 15 minutos y lo des insuflamos por 5 minutos (1). Repetimos alrededor de 4 veces la misma maniobra logrando una expansión cutánea y permitiéndonos además claro de la disección realizada en dicha región, que la colocación del esqueleto cartilaginoso tallado sea de una manera más fácil o sencilla y la presión ejercida sobre el neo cartílago sea menor ya que este segmento cutáneo no es muy distensible. Esta maniobra es realizada por la instrumentadora en cuanto nos encontramos efectuando la retirada del segmento cartilaginoso de la parrilla costal. (Figura 5.)
(Figura 5.)

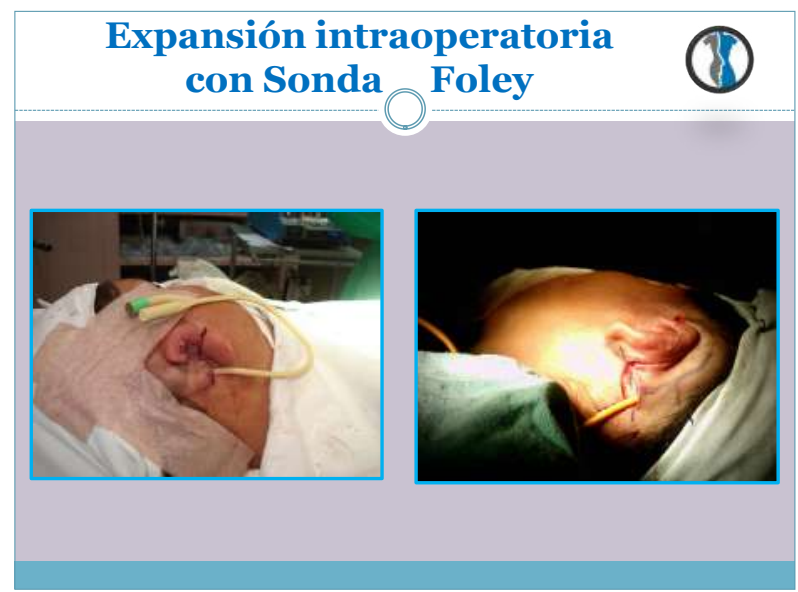

Siempre ocupamos un retazo pequeño o un pedacito de una radiografía a manera de "molde-guía" tomada como referencia de la oreja contra lateral sana que nos sirve de modelo durante el tallado manual del nuevo esqueleto cartilaginoso, la cual dejamos 20 minutos en "Sidex" antes de ser utilizada. En la imagen inferior podemos observar el cartílago costal pintado con azul de metileno para efectos didácticos donde resaltados principalmente la curvatura del hélix.

(Figura 6).

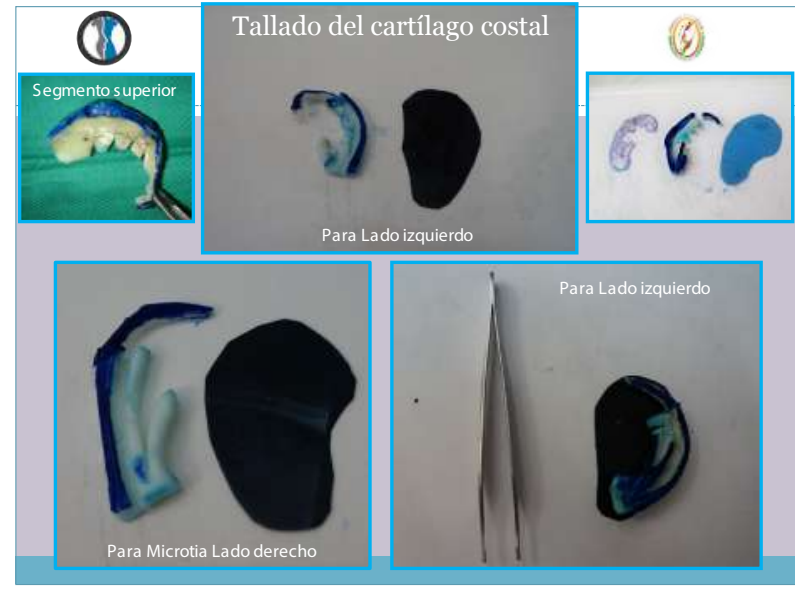

\section{En resumen:}

Primero: Realizamos la retirada del esbozo de cartílago embrionario así como creamos el túnel subcutáneo por donde vendrá el neo cartílago tallado y la consiguiente expansión con la sonda Foley, durante 3 a 4 sesiones, la cual es controlada por la instrumentadora.

Segundo: Iniciamos a través de una incisión similar a la de Kocher (subcostal derecha)la retirada del segmento cartilaginoso preservando al máximo el pericondrio, cerrándolo por planos, ejecutamos la "prueba del neumático" para descartar neumotórax, dejamos un drenaje tipo "pen rose“ pequeño subcutáneo y cerramos hasta la piel. 
Tercero: Paralelamente en cuanto un equipo se encuentra realizando el cierre de la pared abdominal yo inicio el tallado del nuevo segmento cartilaginoso. Una vez finalizado colocamos el nuevo esqueleto cartilaginoso en el túnel subcutáneo y rotamos el esbozo de lóbulo mal posicionado embrionariamente a una situación más anatómica para que en el segundo tiempo realicemos la disección en bloque de todo el segmento y tengamos nuestra oreja reconstruida finalmente. $(1,2,3,4,5)$.

Todo el procedimiento es realizado bajo anestesia general. Los pre operatorios requeridos son una evaluación cardiológica pre operatoria por un cardiólogo infantil, laboratorios sanguíneos de rutina, rayos $x$ de tórax frente y o perfil. Y la mayoría de los pacientes sino casi todos ya han realizado pruebas de audiometrías presentando en su mayoría alteración auditiva en diferentes porcentajes.

El tiempo operatorio oscila entre 3 a 4 horas como termino en el primer tiempo quirúrgico, el tiempo de internación hospitalaria es de tres días. Y el seguimiento clínico quirúrgico lo realizo en mi consultorio privado ya que no desempeño mi actividad profesional en ningún nosocomio público municipal o del estado.

\section{Resultados}

En las imágenes siguientes podemos evidenciar dos casos de microtias severas, el primero en un adolescente de 17 años (figuras 7 y 8) en quien hemos aplicado factores autologos regeneradores de tejidos como la Fracción Vascular Estromal (FVE) obtenida por aspiración de médula ósea esternal y vertido en el mismo lecho pericondrial al momento de cerrar la pared costal y reparar el pericondrio, como se evidencia en la foto\# 3 de la figura 7.

Estos 2 casos ya fueron relatados en el primer volumen de la revista Boliviana de Cirugía Plástica y presentado en varios congresos nacionales y regionales de Latino América organizados por nuestra Federación, al hablar de nuestra experiencia en la aplicación de factores autólogos regeneradores así como la utilización de la FVE y plasma rico como medio regenerador de tejidos en el Congreso Brasilero de Células Madre e Ingeniería de Tejidos, realizado el 2010 en el Hospital Santa Catarina en Sao Paulo, Brasil y también en el Congreso Mundial de IPRAS en Chile del 2013. Aplicamos entonces en el lecho receptor del neo cartílago tallado, plasma rico en plaquetas con el objetivo de alcanzar una integración mayor y una menor absorción del segmento injertado y auxiliar en la revascularización local en el colgajo. (Foto \# 4 de la figura 7 ).
(Figura 7).

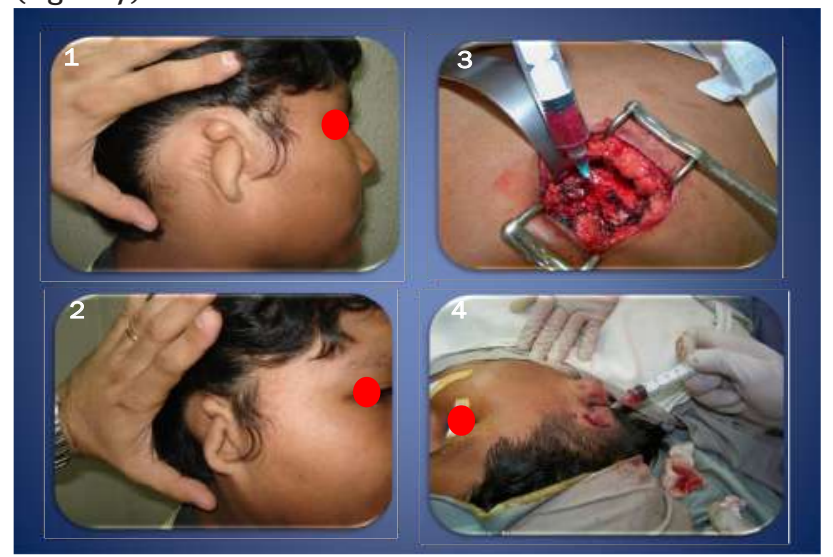

En la figura 8 observamos una reconstrucción tomográfica tridimensional realizada al 4 to mes post operación del primer tiempo, la cual reporta presencia de tejido de neo formación pero de menor densidad que el cartílago.

(Figura 8).

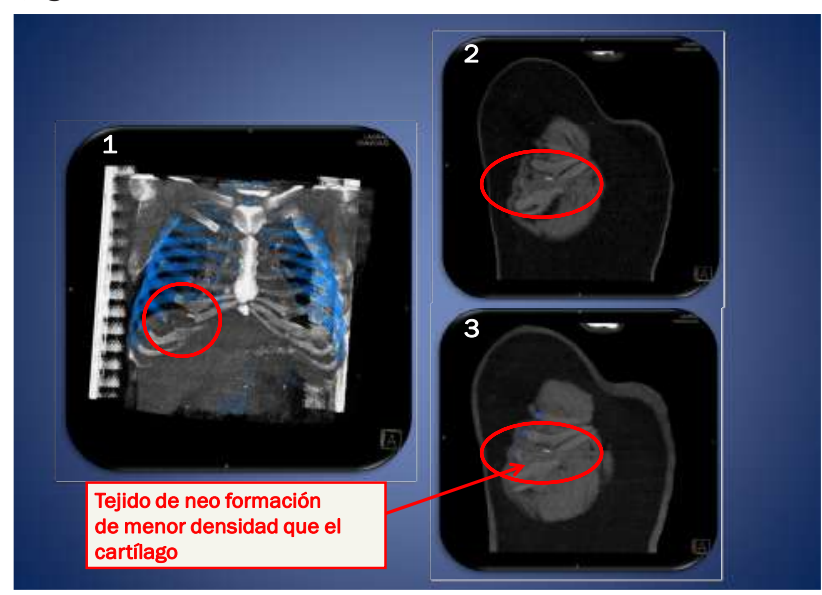

(Figura 9).

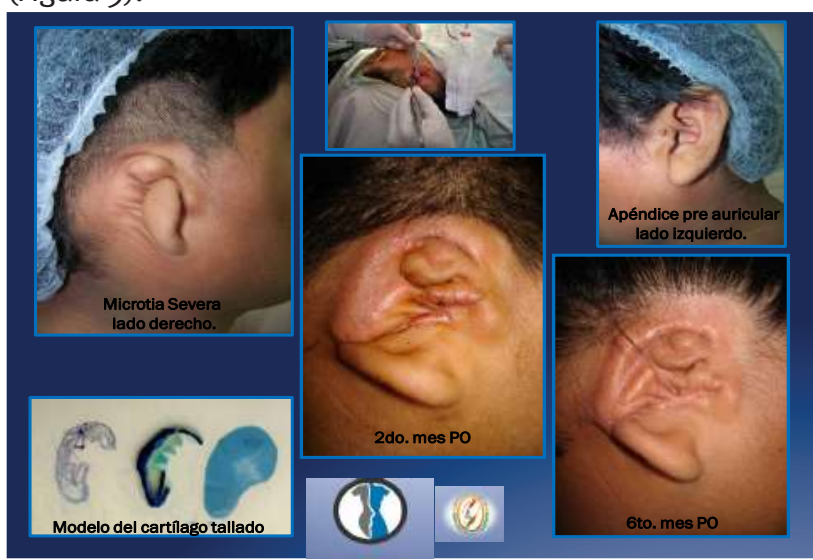

En la Figura 10, el segundo caso, un paciente de 42 años con microtia severa, realizamos la reconstrucción del pabellón y aplicamos la FVE en el lecho pericondrial, al 4 to mes solicitamos una tomografía de tórax, la cual reporto un punto de osificación en el segmento donde se aplico la FVE. Lo que nos lleva a concluir de que debido a la edad adulta del paciente y como los tejidos se encuentran más endurecidos, 
fibrosados y hasta incluso calcificados u osificados, hecho que dificulto también el tallado del nuevo cartílago...era de suponer que encontraríamos en el segmento donde retiramos el cartílago y aplicamos la FVE, un neo tejido cicatricial pero mayormente más osificado y no así cartílago neo formado como quizás lo esperábamos. Como se observa en la tomografía de la figura 11 . Y lo reporta el resultado anatomo patológico.

En la Figura 10, imagen 4 también observar al 6to mes de PO del primer tiempo quirúrgico el pabellón parcialmente reconstruido, el lóbulo rotado y el EXCESO DE PIEL característico en el tercio superior de la Microtia que NO ES PREFERENTEMENTE RESECADA durante el primer tiempo ya que considero que esos retoques bien pueden realizarse durante el segundo tiempo y/o mejor si se los realiza en el tercer tiempo ya que ese excedente de piel a pesar de no otorgar parcialmente un resultado de afinamiento estético y en caso se presente cualquier complicación siempre podrá contarse con esa piel excedente y concluir así con el resultado evitando catástrofes.

(Figura 10).
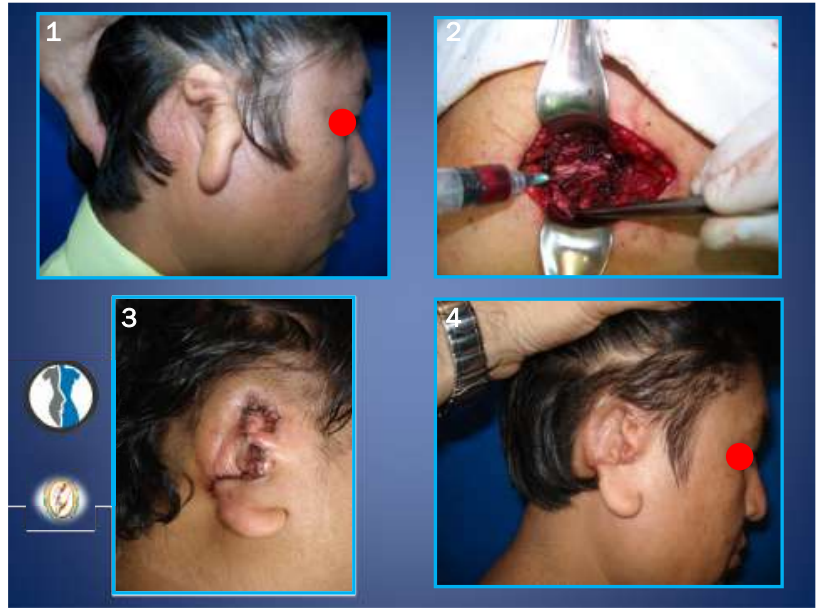

(Figura 11).

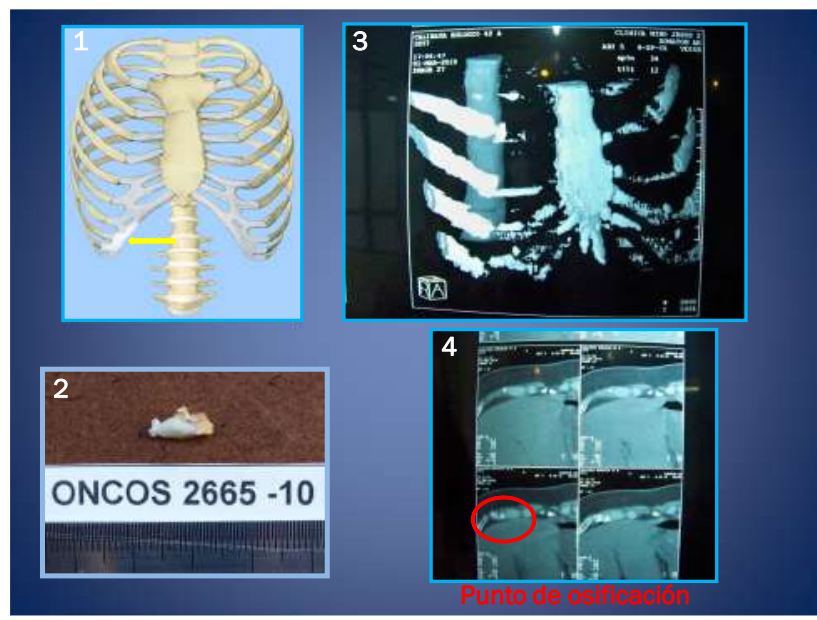

Cuando realizamos el segundo tiempo operatorio, tomamos una biopsia en el lugar de donde fue retirado el seg- mento cartilaginoso para la reconstrucción, el mismo local donde habíamos colocado la FVE, es decir donde la tomografía solicitada al 4 to mes de $\mathrm{PO}$, nos reportaba como foco de tejido osificado y obtuvimos como resultado de la patología lo siguiente (Figura 12): Fragmento de cartílago hialino con cambios reparativos y reemplazo por tejido fibroconectivo vascularizado, además de la presencia de FOCO PERIFÉRICO DE CALCIFICACIÓN como lo demostró la tomografía en la imagen 4 de la figura 11. ( foco de osificación).

(Figura 12).

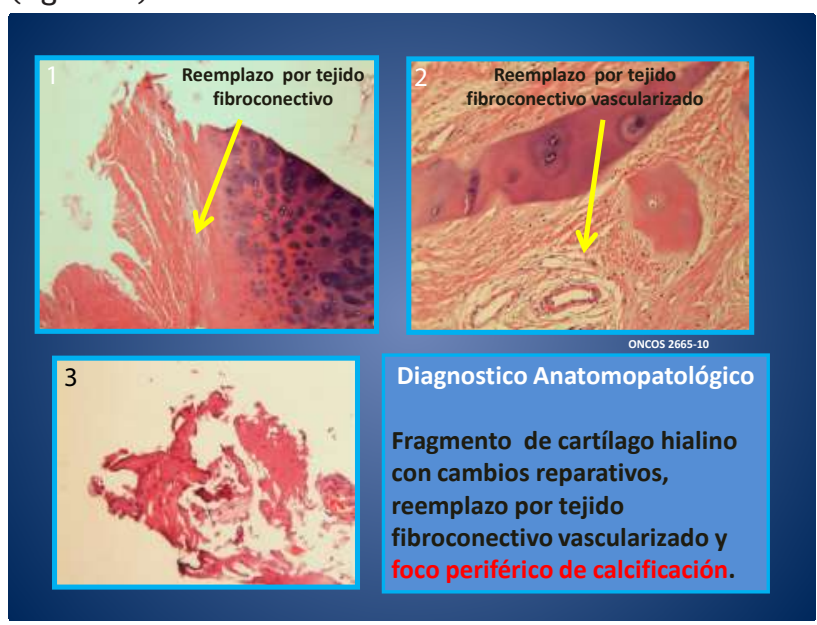

En la Figura inferior (Figura 13) podemos apreciar una microtia moderada de Avelar o una "Constricted Ear" de Tanzer según la clasificación descrita (1), donde observamos todo el hélix retorcido, aunque presencia de lóbulo de oreja bien posicionado, trago y CAE presente. Simplemente reconstruimos el tercio superior de la oreja con la misma técnica del tallado de Avelar.

(Figura 13.)

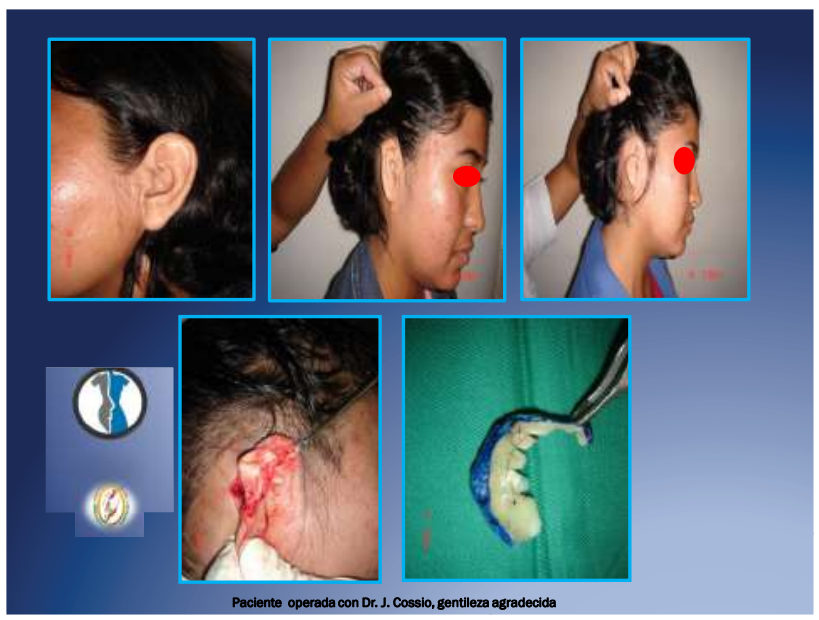

(Figura 14).

Paciente de sexo femenino, 38 años, portadora de Microtia severa de Avelar, primer tiempo quirúrgico. Presenta además de características típicas de una Microtia severa, un esbozo de CAE, es decir apenas un fondo de saco de 3 mi- 
límetros de profundidad. En este caso fue muy difícil la obtención y el tallado del esqueleto cartilaginoso encontrando un cartílago muy osificado, factor que limita desde luego el resultado estético. Inclusive podemos observar que hasta el color del cartílago es más amarillento y no blanquecino como se presenta en la niñez.

(Figura 14).

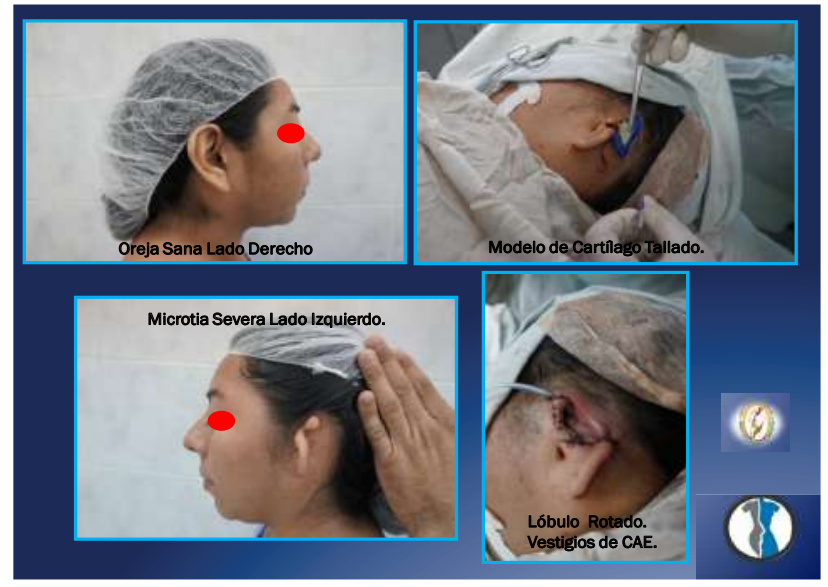

Otro caso de Microtia Severa lado izquierdo, paciente masculino de 7 años.

(Figura 15).

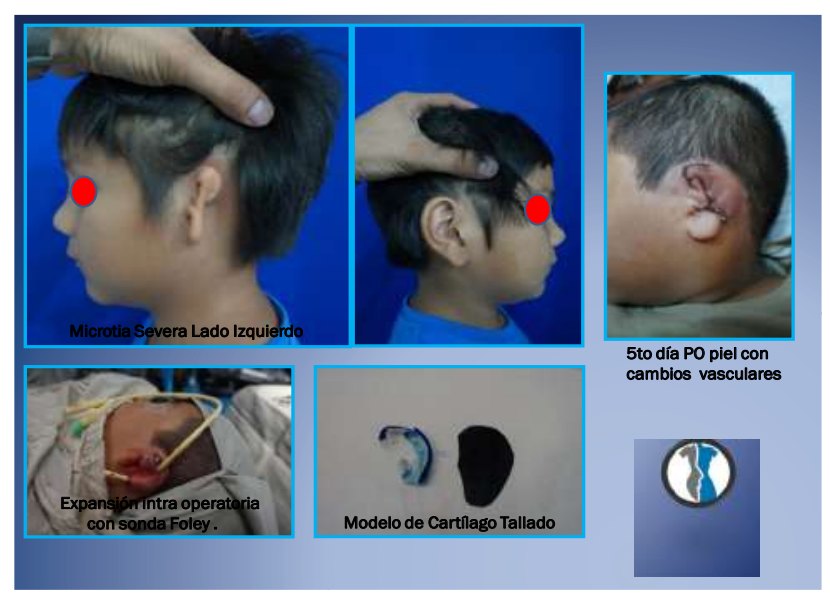

En la figura 16 observamos un caso de Microtia severa (Figura 16).el modelo del cartílago tallado de Avelar, la expansión con la sonda Foley el cierre del pericondrio costal, una fistula cutánea de origen embrionaria que tuvo que ser resecada. Solo en muy pocos casos resecamos la piel sobrante de la oreja durante el primer tiempo, pues como fue mencionado es probable que se utilice este exceso cutáneo en el segundo tiempo de reconstrucción y optamos normalmente por no resecarla. A pesar de realizar una pequeña disección en el túnel subcutáneo dejo un drenaje espirativo, tipo sonda K por 24 horas para lograr que la piel se calque mejor sobre el cartílago injertado.

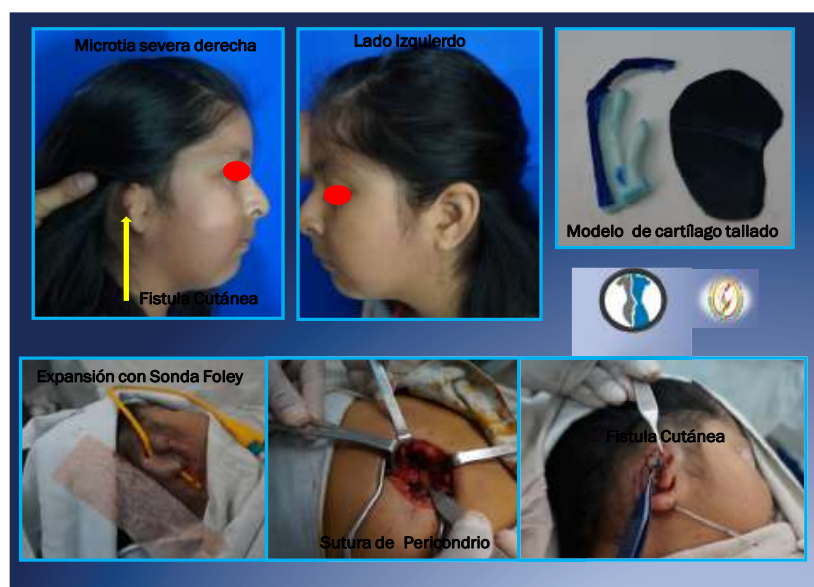

\section{Conclusiones}

La mejor edad para operar cualquier patología del pabellón auricular es sin duda a partir de los 6 a 8 años dependiendo claro del grado de evolución física de cada niño, del tamaño de la oreja contra lateral y del tórax.

El tiempo operatorio para esta operación (primer tiempo reconstrucción del pabellón) fue de 3 a 4 horas y media bajo anestesia general.

Optamos siempre por la utilización de tejidos autologos y la retirada del futuro esqueleto cartilaginoso del lado derecho entre la 8ava. y gna. costilla pues simplemente se evierte el segmento cartilaginoso retirado y se lo talla para el lado izquierdo sin ningún problema.

En los casos presentados donde los pacientes fueron adultos lógicamente la dificultad a la hora del tallado del cartílago fue mayor limitando claro el resultado estético previsto.

No he presentado complicaciones graves durante el primer tiempo quirúrgico como neumotórax o lesión hepática, o hematomas de la pared muscular abdominal que requieran drenajes inmediatos, ni procesos infecciosos que sean catastróficos, sino apenas los clásicos para cualquier otro acto quirúrgico como Seroma leve en el lecho donador.

Los pacientes de sexo masculino tuvieron una incidencia mayor de microtias del lado derecho aunque también se presentaron esporádicamente casos del lado izquierdo.

En las pacientes de sexo femenino la incidencia de las diversas microtias operadas se presentaron más en el lado izquierdo y con una leve tendencia a la bilateralidad con manifestaciones diversas como la presencia de Microtia severa y moderada hasta la presencia de apéndices pre auricular.

No he tenido pacientes con otras malformaciones sindrómicas como el Sindrome de Treacher- Collins por ejemplo u otras malformaciones. Sino apenas alteraciones en la audición del lado afectado de las más diversas, tomando en cuenta que actualmente mi experiencia es en la medicina privada y no trabajo en hospital público y los pacientes operados vienen como referencia de otros colegas amigos cirujanos plásticos, pediatras, otorrinos o cirujanos de cabeza cuello y ya cuentan con tomogra- 
fías previas y evaluaciones fono auditivas correspondientes. En el presente artículo no hago referencia de casos de reconstrucción de orejas por trauma y aunque la técnica del tallado es la misma, amerita un capítulo aparte para describir muchos casos interesantes.

En los dos primeros casos presentados y descritos donde utilizamos Factores autologos regeneradores de tejidos, como la Fracción Vascular Estromal(FVE) obtenida de la medula ósea por punción del hueso esternal, fue demostrado por estudios de anatomía patológica y tomografía tridimensional que hubo crecimiento de un tejido reparativo de neo regeneración y en el caso del paciente de 42 años se presento un foco periférico de calcificación y lo mismo reporto la tomografía al 4 to mes de realizado el primer tiempo. Sabemos que al preservar el pericondrio habrá neo formación de tejido cartilaginoso que puede tener la presencia de tejido colágeno y ser muy similar a un cartílago fibrosado pero se han escrito y relatado tantas experiencias usando tejidos autologos que estos tejidos propios que son "Factores Regeneradores" podrían tan solo reforzary acelerar la neo formación de cualquier tejido donde se los aplique sin causar en el paciente ningún efecto nocivo al ser factores autologos que normalmente intervienen en la cicatrización y o regeneración normal de nuestros tejidos.

La cirugía reconstructiva del pabellón auricular es siempre un reto gigantesco para el cirujano plástico que requiere además de destreza propia, una enseñanza dirigida, una afición característica y un amor profundo por lo que se hace pues tiene un alto grado de insatisfacciones en cuanto a resultados estéticos, a la expectativa que el paciente desea alcanzar, a pesar de ser muy claro y objetivo durante la entrevista en la consulta.

Particularmente creo que me falta mucho por aprender, que mis manos son aun torpes a la hora de tallar la nueva oreja y que aun la pequeña experiencia manifestada en este articulo me lleva a buscar horizontes claros, estudiar y mejorar cada día más. Penosamente no es una cirugía muy frecuente en nuestro medio.

\section{Agradecimientos.}

Deseo dedicar este articulo al Dr. Juárez Moraes Avelar de Sao Paulo, Brasil con quien tuve la bendición de poder aprender y apasionarme con este segmento de la cirugía reconstructiva. La foto de abajo fue tomada en septiembre del año 2015 durante el Congreso Regional Bolivariano de la FILACP, organizado por la Sociedad Boliviana de Cirugía Plástica, en la ciudad de Santa Cruz de la Sierra. El profesor compartió conmigo en un gesto muy humano, recordando un momento muy feliz de su vida, cuando juró como médico cirujano, encontrando un sillón muy similar al de aquella época trayéndole recuerdos inolvidables.

Gracias por su sabiduría en mi depositada, seré siempre grato por su bondad, su paciencia y su increíble gesto paternal al momento de enseñarme.

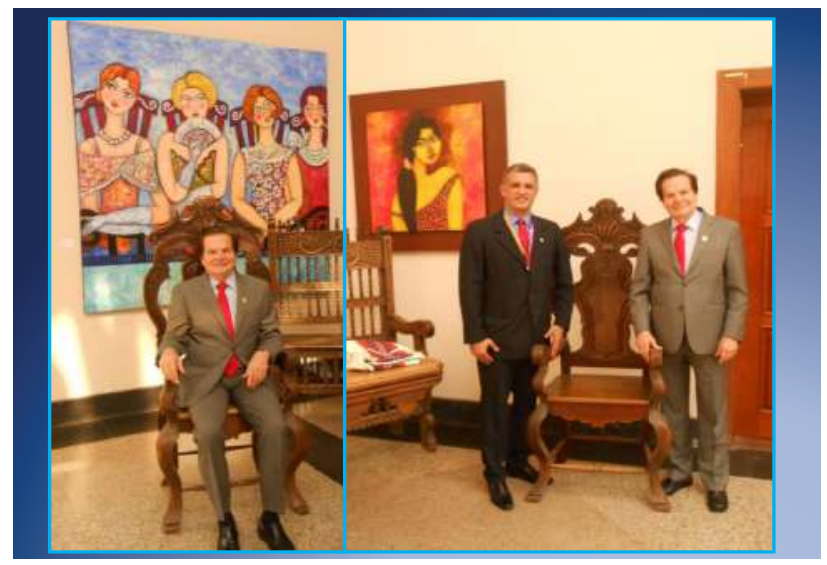

\section{Reconocimiento:}

No puedo dejar de reconocer a quienes fraternalmente hacen parte de mi equipo y me apoyan en el día a día, sin ellos nada podría ser ejecutado.

Asistentes: Dr. Raúl Escobar Ugarte, Cirujano Plástico. Dr. Sergio Ballivian, Cirujano General. Anestesiologos: Dr. Roger Banegas Cuellary Dr. Jorge Meschwitz Lopez. Instrumentadoras: Dra. Inst. Maribel Coca y Lic. Inst. Pahola Paz.

\section{Bibliografía.}

1. Avelar,JM. Creation of the Auricle. Editora Hipócrates. 2:21. 3: 39. 4:61. 5:85.7:127.

1997.

2. Avelar,JM. Cirugía Plástica Obrigacao de Meio e Nao Obrigacao de Fim ou Resultado. Sao Paulo: Ed. Hipócrates, 2000.

3. Avelar,JM. Reconstrucao Auricular nas Microtias- Técnica Pessoal, parte B. Cirurgia Plástica Fundamentos e Arte, Cirurgia Reparadora de Cabeca e Pescoco . José Marcos Mélega. Editora Guanabara Koogan. Rio de Janeiro.73: 972-992. 2002.

4. Avelar, JM. Estagio Atual da Reconstrucao da Orelha. Atualizacao em Cirurgia Plástica Estética e Reconstrutiva. Sociedade Brasileira de Cirurgia Plástica, Regional Sao Paulo. Robe Editorial. 35:299-310. 2005.

5. Avelar,JM. Reconstrucción del Pabellón Auricular, IX Congreso Regional Bolivariano de Cirugía Plastica, FLACP. Santa Cruz de la Sierra, Bolivia. Septiembre 2015.

6. Brent, B. The Correction of Microtia with Autogenous Cartilage Grafts: I the classic Deformity. Plast Reconstr Surg. 66: 1. 1980.

7. Brent, B. The Correction of Microtia with Autogenous Cartilage Grafts: Atypical and Complex Deformities. Plast Reconstr Surg. 66:13. 1980.

8. Brent, B. Byrd, HS. Secondary Ear Reconstruction with Cartilage Grafts Covered by Axial, Ramdom, and Free Flaps of Temporoparietal Fascia. Plast Reconstr Surg. 72: 141. 1983.

9. Firmin, F. Reconstruction for Microtia. Scand J Plast Reconstr Surg. 32: 35-77. 1998.

10. Nagata, S. Modification of the Stages in Total Reconstruction of the Auricle: Part I. Graftting the Three-Dimensional Costal Cartilage Frameworkfor Lobule-type Microtia. Plast Reconstr Surg. 2: 221-230. 1994.

\section{Dirección del autor.}

Dr. Darío Lautaro Suárez Oyhamburú. Calle Manuel Ignacio Salvatierra 466. Entre Potosí y Tarija, Edificio Ey E. Depto 2, Bloque“"B”, Planta Baja. 5913 3304499. Cel/Ws - 591 709-48888. Email. dariocirujano@yahoo. com.ar, Web. www.drdariosuarez.com, Santa Cruz de la Sierra, Bolivia. 